\title{
In Vitro and In Vivo Effects of Deoxyribonucleic Acid-Based Coatings Funtionalized with Vascular Endothelial Growth Factor
}

\author{
JEROEN J.J.P. VAN DEN BEUCKEN, ${ }^{1}$ X. FRANK WALBOOMERS, ${ }^{1}$ SUZAN T.M. NILLESEN, ${ }^{2}$ \\ MATTHIJN R.J. VOS, ${ }^{3}$ NICO A.J.M. SOMMERDIJK, ${ }^{3}$ TOIN H. VAN KUPPEVELT, ${ }^{2}$ \\ ROELAND J.M. NOLTE, ${ }^{3,4}$ and JOHN A. JANSEN ${ }^{1}$
}

\begin{abstract}
Vascularization is important in wound healing and essential for tissue ingrowth into porous tissueengineering matrices. Furthermore, peri-implant tissue vascularization is known to be important for the functionality of subcutaneously implanted biosensors (e.g., glucose sensors). As a first exploration of the use of deoxyribonucleic acid (DNA)-based coatings for the optimization of biosensor functionality, this study focused on the effect of DNA-based coatings functionalized with vascular endothelial growth factor (VEGF) on in vitro endothelial cell behavior and vascularization of the peri-implant tissue in vivo. To that end, DNAbased coatings consisting of poly-D-lysine and DNA were functionalized with different amounts of VEGF (25 and $250 \mathrm{ng}$ ) and compared to non-coated controls and non-functionalized DNA-based coatings. The results demonstrated the superiority of VEGF-functionalized DNA-based coatings in increasing endothelial cell proliferation and migration in vitro over non-coated controls and non-functionalized DNA-based coatings. In vivo, a significant increase in vascularization of the peri-implant area was observed for VEGFfunctionalized DNA-based coatings. Because no dosage-dependent effects were observed, future experiments should focus on optimizing VEGF concentration for this purpose. Additionally, the administration of VEGF in combination with other (pro-angiogenic) factors should be considered.
\end{abstract}

\section{INTRODUCTION}

A N IMPORTANT PHYSIOLOGICAL ASPECT of healing around biomaterials is vascular development. For tissueengineering matrices, particularly those that are pre-seeded with cells, fast development of a vascular network is required for tissue ingrowth and cell survival. Also, for solid devices such as subcutaneously implantable biosensors, the development of a contiguous vascular network is important for their functionality. ${ }^{1,2}$ For instance, previous studies have demonstrated that the formation of a largely avascular fibrous tissue capsule and the resulting increased diffusion distance between sensor and blood supply to the sensor surrounding tissue diminishes the responsiveness of implanted biosensors to fluctuations in analytes in the interstitial fluid. ${ }^{1,2}$ Furthermore, Gerritsen et al. showed that inflammatory cells and low-molecular-weight serum components influence the performance of amperometric glucose sensors. ${ }^{3}$ The basis for these findings was the secretion of enzymes by stimulated granulocytes, which consumed the hydrogen peroxide formed by the oxidation of glucose, and the formation of a diffusional barrier for glucose and the inhibition of glucose oxidase activity by serum components. Consequently, the authors of these publications suggested

\footnotetext{
${ }^{1}$ Department of Periodontology and Biomaterials, Radboud University Nijmegen Medical Center, Nijmegen, The Netherlands.

${ }^{2}$ Department of Biochemistry, Nijmegen Center for Molecular Life Sciences, Radboud University Nijmegen Medical Center, Nijmegen, The Netherlands.

${ }^{3}$ Laboratory for Macromolecular and Organic Chemistry, Eindhoven University of Technology, Eindhoven, The Netherlands.

${ }^{4}$ Department of Organic Chemistry, Radboud University Nijmegen, Nijmegen, The Netherlands.
} 
that biosensor functionality is likely to improve if the vascularity in the direct vicinity of the device is increased and inflammatory responses to the device are minimal.

The development of the vasculature depends on two processes (vasculogenesis and angiogenesis), which are responsible for de novo vessel formation and sprouting from already existing vessels, respectively. ${ }^{4}$ Therapeutical modulation of vascular supply, however, is limited to angiogenesis, because vasculogenesis is believed to occur only during early embryogenesis. Angiogenesis is a complex process that involves subtle interactions between cells, extracellular matrix components, and regulatory molecules. Decisive steps in this process are the localized proteolytic degradation of the subendothelial basement membrane, migration of endothelial cells, the formation of sprouts, remodeling of extracellular matrix, and the formation of anastomoses, which together precede the establishment of blood flow. ${ }^{5}$ The delivery of growth factors with pro-angiogenic action is a potentially powerful tool in control over vascular development. A widely used pro-angiogenic growth factor in tissue engineering is vascular endothelial growth factor (VEGF). ${ }^{6}$ VEGF affects endothelial cells through positive effects on proliferation, migration, tubule formation, survival, and integrin expression. ${ }^{7}$

To increase vascularity around subcutaneously implanted biosensors, we hypothesized that VEGF functionalization of deoxyribonucleic acid (DNA)-based coatings could be beneficial. It has been demonstrated that these coatings, whose generation is based on the layer-by-layer deposition of cationic poly-D-lysine (PDL) or poly(allylamine hydrochloride) with anionic $\mathrm{DNA}^{8},{ }^{2}$ are fully histocompatible upon subcutaneous implantation, showing no adverse reactions in terms of inflammation and wound healing. ${ }^{9,10}$ Furthermore, it was shown that these DNA-based coatings are suitable for functionalization with bone morphogenetic protein 2 (BMP2), an osteo-inductive factor, using different loading modalities and that this factor retained its biological activity. ${ }^{11}$ Another important feature of the fabrication method of these DNA-based coatings is its simplicity, which allows a wide variability of substrate materials (e.g., ceramics, metals, and polymers) with almost unrestricted substrate geometry. ${ }^{12}$

In view of the described disadvantageous effects of lack of vascularity on biosensor functionality, we hypothesized that VEGF functionalization of DNA-based coatings would be beneficial for the vascularization of the peri-implant tissue. Consequently, the aim of this study was to evaluate the effect of VEGF-functionalized DNA-based coatings on endothelial cell behavior in vitro and vascular development in vivo. Therefore, [PDL/DNA $]_{5}$ coatings on glass substrates were functionalized with a small (25 $\mathrm{ng}$ ) or large (250 ng) amount of VEGF to study dosage-dependent effects. These VEGF-functionalized DNA-based coatings, as well as nonfunctionalized coatings and non-coated controls, were used in an in vitro experiment to study the proliferation, migration, and morphology of endothelial cells. Additionally, these four types of substrates were implanted in the backs of rats in an in vivo animal model to study vascular development in the direct vicinity of the implants.

\section{MATERIALS \& METHODS}

\section{Materials}

Polyanionic salmon DNA ( $\pm 300 \mathrm{bp} /$ molecules; sodium salt) was kindly provided by Nichiro Corporation (Kawasaki, Japan). Potential protein impurities in the DNA were checked using the bicinchoninic acid (BCA) protein assay (Pierce, Rockford, IL) and were measured to be below $0.20 \%$ w/w (data not shown). Polycationic polyelectrolyte PDL (mw 30,000-70,000) was purchased from Sigma (SigmaAldrich Chemie B.V., Zwijndrecht, the Netherlands). All materials were used without further purification.

\section{Substrate preparation and cleaning}

Disc-shaped glass substrates $(12 \mathrm{~mm}$ diameter; $1.5 \mathrm{~mm}$ thickness; Waldemar-Knittel Glasbearbeitung GmbH, Braunschweig, Germany) were cleaned in Piranha solution (hydrogen peroxide $\left(\mathrm{H}_{2} \mathrm{O}_{2}, 30 \%\right.$ aqueous solution)/sulfuric acid $-3: 7 \mathrm{v} / \mathrm{v}$ ) to completely remove all traces of organic materials at the surface and to increase the wettability of the surface. Subsequently, the substrates were thoroughly rinsed with ultra-pure water from a Millipore system (resistivity $\geq 18.2$ MW $\times \mathrm{cm}$; Millipore B.V., Amsterdam, The Netherlands) and dried using a pressurized air stream.

\section{Generation of multilayered DNA coatings}

DNA coatings were generated using layer-by-layer deposition, as described previously. ${ }^{8}$ Briefly, the substrates were immersed in an aqueous solution of PDL $(0.1 \mathrm{mg} / \mathrm{mL})$ for $30 \mathrm{~min}$, allowing sufficient time for the adsorption of the first cationic polyelectrolyte layer onto the substrates. Subsequently, substrates were washed in ultra-pure water ( 5 min; continuous water flow) and dried using a pressurized air stream. Thereafter, substrates were alternately immersed in an anionic aqueous DNA solution $(1 \mathrm{mg} / \mathrm{mL})$ and the PDL solution for $7 \mathrm{~min}$ each, with intermediate washing in ultrapure water and subsequent drying using a pressurized air stream to obtain final coating architecture of [PDL/DNA $]_{5}$. (The number indicates the number of double layers.)

\section{Experimental groups}

Non-coated substrates and $[\mathrm{PDL} / \mathrm{DNA}]_{5}$-coated substrates were sterilized using an ultraviolet treatment $(254 \mathrm{~nm} ; 4 \mathrm{~h})$. Subsequently, VEGF functionalization of $[\mathrm{PDL} / \mathrm{DNA}]_{5^{-}}$ coated substrates was carried out as described below. The experimental groups used in this study were controls (noncoated glass substrates), [PDL/DNA $]_{5}$ (glass substrates with a $[\mathrm{PDL} / \mathrm{DNA}]_{5}$-coating), [PDL/DNA $]_{5}-\mathrm{VEGF} 25$ ([PDL/DNA $]_{5^{-}}$ coated glass substrates with $25 \mathrm{ng} \mathrm{VEGF})$, and [PDL/DNA $]_{5-}$ VEGF250 ([PDL/DNA $]_{5}$-coated glass substrates with $250 \mathrm{ng}$ VEGF). 


\section{Functionalization with VEGF}

Recombinant rat VEGF (rrVEGF $164 ; 164$ amino acids; Department of Biochemistry, Radboud University Nijmegen Medical Center, Nijmegen, The Netherlands) was serially diluted in phosphate-buffered saline (PBS), after which 25 or $250 \mathrm{ng}$ of VEGF was applied in $10-\mu \mathrm{l}$ aliquots to the sterilized [PDL/DNA $]_{5}$-coated substrates. Because of the iso-electric point of VEGF ( $\mathrm{pI} 8.5$ ), ${ }^{13}$ it is positively charged at neutral $\mathrm{pH}$ and shows similar interaction with the negatively charged DNA top-layer in the multilayered structure as observed previously for BMP-2. ${ }^{11}$ The solvent was evaporated during incubation at $37^{\circ} \mathrm{C}$.

\section{In vitro experiments}

Cell culture and seeding. Human umbilical vein endothelial cells (HUVECs; PromoCell GmbH, Heidelberg, Germany) were expanded in growth medium containing basic fibroblast growth factor $(1 \mathrm{ng} / \mathrm{mL})$, endothelial cell growth supplement/heparin $(0.4 \% \mathrm{v} / \mathrm{v})$, epidermal growth factor $(0.1 \mathrm{ng} / \mathrm{mL})$, hydrocortisone $(1 \mu \mathrm{g} / \mathrm{mL})$, phenol red $(0,62$ $\mathrm{ng} / \mathrm{mL}$ ), and fetal calf serum (FCS; $2 \% \mathrm{v} / \mathrm{v}$ ) (PromoCell $\mathrm{GmbH})$. To increase cell attachment, before cell seeding the experimental substrates were incubated for $1 \mathrm{~h}$ at $37^{\circ} \mathrm{C}$ in assay medium (AM; alpha-minimal essential medium; Gibco, Invitrogen Corporation, Breda, The Netherlands), supplemented with $10 \%$ v/v FCS and gentamycin $(50 \mu \mathrm{g} / \mathrm{mL}))$. For each experimental run, cells were seeded at a density of $20 \times 10^{3}$ cells $/ \mathrm{cm}^{2}$ and maintained in AM to exclude potential effects of factors supplemented in growth medium. Medium was refreshed at 1 day after cell seeding and thereafter 3 times per week.

Proliferation of endothelial cells. At selected times after cell seeding (1, 4, 7, and 10 days post-seeding), cells were trypsinized and counted using a Coulter counter (Beckman Coulter Inc., Fullerton, CA, USA). Data were obtained from 2 independent experimental runs with triplicate samples for each condition and time point $(n=3)$.

Morphology of endothelial cells. Parallel to the proliferation assays, 2 independent runs to study endothelial cell morphology were conducted. In each of these runs, 2 experimental samples for each condition at each time point were seeded with HUVECs at a density of $20 \times 10^{3} \mathrm{cells} / \mathrm{cm}^{2}$ and incubated for 3 and 10 days. After these culture periods, cell layers were washed twice with PBS, fixed with $2 \%$ glutaraldehyde, and dehydrated in a graded series of ethanol. Finally, cell layers were dried using tetramethylsilane, sputtercoated with gold, and morphologically examined using a scanning electron microscope (JEOL 6310, JEOL Europe BV, Nieuw-Vennep, The Netherlands).

Migration of endothelial cells. The migrational behavior of endothelial cells (HUVECs) was assessed in 1 experi- mental run using a commercially available in vitro endothelial cell migration assay platform (BD BioCoat Angiogenesis System: Endothelial Cell Migration; BD Biosciences, Bedford MA), according to the manufacturer's instructions. The assay measures the migration of cells (located in an insert) through a microporous membrane toward medium (with or without supplement) in the well. Briefly, [PDL/ DNA $]_{5}$-VEGF25 and [PDL/DNA $]_{5}$-VEGF250 experimental substrates $(n=3)$ were placed in a 24-well plate and incubated with $1 \mathrm{~mL}$ AM for 1, 4, 7, 10, and 14 days. At each time point, the medium was collected, after which fresh medium was added to each experimental substrate for subsequent VEGF release. Collected medium was stored at $-80^{\circ} \mathrm{C}$ until use in the migration kit. For the assay, $225 \mu \mathrm{L}$ of collected medium was added in duplicate in a 96-well plate. Subsequently, HUVECs were added to each insert $\left(25 \times 10^{3}\right.$ cells in $75 \mu \mathrm{l}$ of AM $2 \%$ bovine serum albumin (BSA)), whose content was separated from the well volume using a fluorescence-blocking microporous $(3 \mu \mathrm{m})$ poly(ethylene terephthalate) (PET) membrane. The migration of HUVECs was quantified using post-labeling of the cells with calcein$\mathrm{AM}$ and subsequent fluorescence measurements (excitation $485 \mathrm{~nm}$, emission $530 \mathrm{~nm}$ ) of the PET membrane after $22 \mathrm{~h}$ of incubation. For comparison, the migration of endothelial cells toward medium with known amounts of VEGF (standards: range $0-250 \mathrm{ng} / \mathrm{mL}$ ) was measured. Data were corrected for fluorescence values of blanks (inserts without endothelial cells) and expressed as fold migration, which is set at 1 for the lowest VEGF concentration of the standard.

\section{In vivo experiment}

Animals and implantation procedure. For implantation, 200- to 250-g male Wistar rats were used. The animals were housed in the central animal facility at the Radboud University Nijmegen Medical Center (Nijmegen, The Netherlands), observing all national guidelines for care and use of laboratory animals. The animals received chow and water ad libitum. Before the implantation procedure, approval was obtained from the ethical committee for animal experiments at the Radboud University Nijmegen (KUNDEC \#2003-14).

Surgery was performed under general inhalation anesthesia with nitrous oxide, oxygen, and isoflurane. The animals were immobilized and placed in a ventral position. Subsequently, the dorsal skin of the animals was shaved, washed, and disinfected with povidone-iodine. On each side of the vertebral column, 2 paravertebral incisions were made $(\sim 10 \mathrm{~mm})$, after which a subcutaneous pocket was created using blunt dissection with scissors lateral to each incision. The insertion of substrates was performed such that the VEGF-functionalized side faced the dorsal skin. After insertion of an implant, the skin was closed using skin staples (Agraves; InstruVet C.V., Cuijk, The Netherlands). A total of 64 implants (16 implants of each group) were distributed in 16 rats (4 implants per rat) according to a Latin square randomization scheme. 
Implant retrieval and histological preparations. At the end of each implantation period ( 1 or 3 weeks), 8 rats were killed using $\mathrm{CO}_{2}$-suffication. Subsequently, tissue-covered specimens $(n=8$ for each implant type and implantation period) were collected, the implants excised from the tissue capsule and checked for potential tissue remains using scanning electron microscopy as described previously, ${ }^{9,10}$ and the implant-surrounding tissue processed for embedding in paraffin. Paraffin sections were analyzed histologically (hematoxylin/eosin staining) to obtain complete descriptions of the observed thin sections.

Immunohistochemistry. In parallel with the hematoxylin/ eosin staining, paraffin sections were used for immunohistochemical staining using an anti-alpha smooth muscle actin (anti- $\alpha$ SMA) antibody. Among other tissues, $\alpha$-SMA is present in blood vessel walls ${ }^{14}$ and myofibroblasts, ${ }^{15}$ and its expression was used to determine the total number of blood vessels in the peri-implant area. Deparaffinated sections were treated with $3 \% \mathrm{H}_{2} \mathrm{O}_{2}$ in PBS for 20 min to block endogenous peroxidase, fixed with $4 \%$ formalin, blocked with $5 \%$ BSA (Sigma), incubated with monoclonal immunoglobulin G2a mouse anti- $\alpha$ SMA (1:1600; Sigma), and incubated with biotinylated donkey anti-mouse secondary antibody (1:500; Jackson Laboratories, West Grove, PA). Staining was performed with a biotin-streptavidin detection system (Vectra Elite kit; Vector Laboratories, Burlingame, CA) for $45 \mathrm{~min}$. Positive controls (rat brain tissue sections with positive staining in previous immunohistochemical procedures) and negative controls (1\% BSA in PBS) were included.

Histological and histomorphometrical evaluation. A light microscope (Leica Microsystems AG, Wetzlar, Germany) was used for histological evaluation of the hematoxylin/ eosin-stained sections. Immunohistochemically (anti- $\alpha \mathrm{SMA}$ ) stained sections were used for histomorphometrical evaluation of the number of blood vessels per area. Computer-based image analysis techniques (Leica Qwin Pro-image analysis software; Leica, Wetzlar, Germany) were used to determine the following parameters in digital images of immunohistochemically stained sections:

- region of interest (ROI): the connective tissue area at the dorsal site of the implant (excluding muscle and fat tissue) in a digital image of approximately $700 \times$ $560 \mu \mathrm{m}$ (original magnification $20 \times$; Fig. 1).

- number of blood vessels (BV): number of positively stained vascular structures (blood vessels) within the ROI.

The values obtained with these parameters were used to determine the vascularization (vessel density, VD):

$$
\mathrm{VD}=\mathrm{BV} / \mathrm{ROI}
$$

For each implant-surrounding tissue section, VD was determined by averaging the numbers of counted vascular
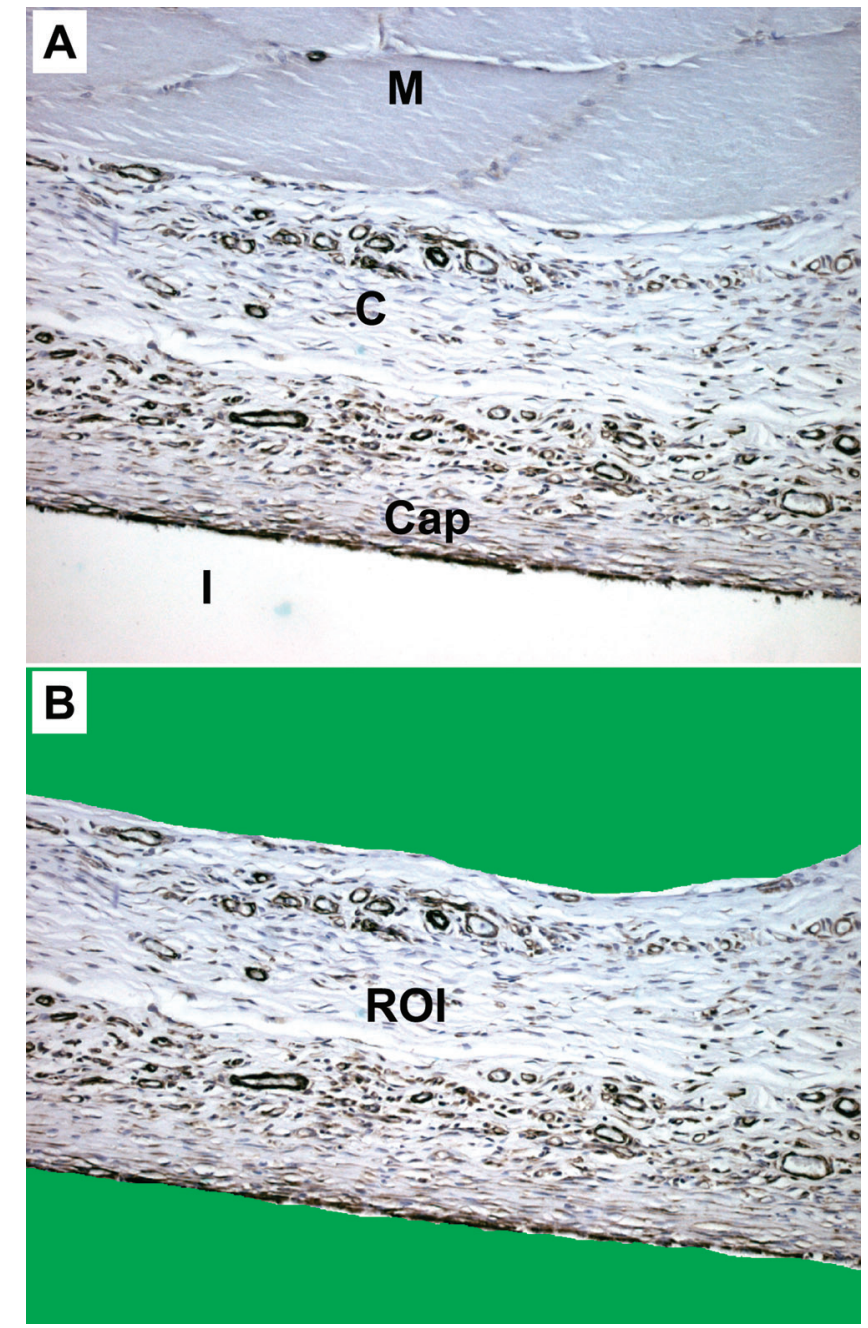

FIG. 1. Schematic overview of histomorphometric parameters in immunohistochemically (anti-alpha smooth muscle actin) stained sections. (A) Representative image showing the original location of the implant (I), the surrounding fibrous capsule (Cap), the connective tissue (C), and muscle tissue (M). (B) Qwin Pro-image analysis software was used to indicate the region of interest (ROI), after which the number of positively stained vascular structures within the ROI was counted. Color images available online at www.liebertpub.com/ten.

structures per ROI of 3 digital images (at $20 \times$ magnification) per tissue section. Eight average VDs were obtained for each group at each time period.

\section{Statistical analysis}

All measurements were statistically evaluated using GraphPad Instat software (version 3.05; GraphPad Instat, San Diego, CA). Statistical analysis was performed using a one-way analysis of variance with a post hoc TukeyKramer multiple comparison test for cell proliferation, migration, and vascularization at individual implantation periods. Vascularization for individual groups and pooled groups at different implantation periods was assessed using 


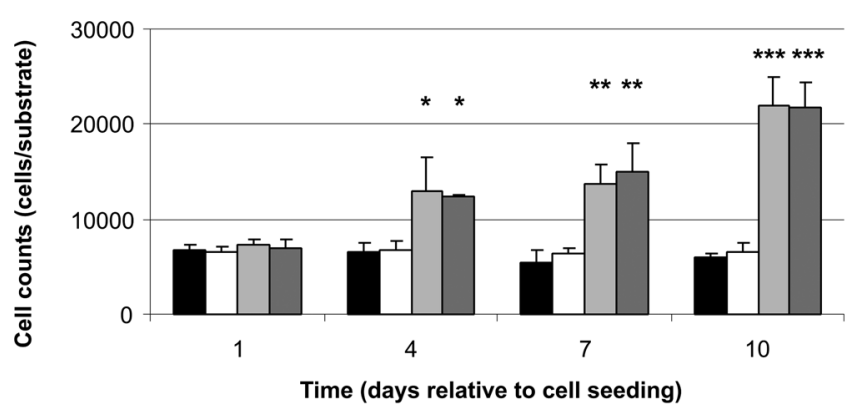

口 control $\square[$ PDL/DNA]5 $\square[$ PDL/DNA]5-VEGF25 $\square[$ PDL/DNA]5-VEGF250

FIG. 2. Proliferation of human umbilical vein endothelial cells (HUVECs) on experimental substrates. Results are shown as means \pm standard deviations of triplicate samples for one representative experiment out of two. ${ }^{*} p<0.05$ compared with controls, ${ }^{* *} p<0.01$ compared with controls, ${ }^{* * *} p<0.001$ compared with controls.

an unpaired t-test. A $p$-value $<0.05$ was considered statistically significant.

\section{RESULTS}

\section{In vitro experiments}

Proliferation of endothelial cells. The 2 independent runs of endothelial cell proliferation showed comparable results. The results of one of these runs are presented in Figure 2. Initial cell numbers (on day 1) showed that comparable numbers of endothelial cells attached to the experimental substrates after cell seeding. From day 4, 7, and 10, however, endothelial cells on [PDL/DNA $]_{5}-\mathrm{VEGF} 25$ and [PDL/ DNA $]_{5}$-VEGF 250 showed statistically significantly more cells than controls and $[\mathrm{PDL} / \mathrm{DNA}]_{5}(p<0.05, p<0.01$, and $p<0.001$ for days 4,7 , and 10 , respectively). Whereas cell numbers on $[\mathrm{PDL} / \mathrm{DNA}]_{5}-\mathrm{VEGF} 25$ and $[\mathrm{PDL} / \mathrm{DNA}]_{5}-$ VEGF250 increased over time, those on controls and [PDL/ DNA $]_{5}$ were constant over time and did not differ statistically from each other $(p>0.05)$. Furthermore, no statistically significant differences were found between [PDL/

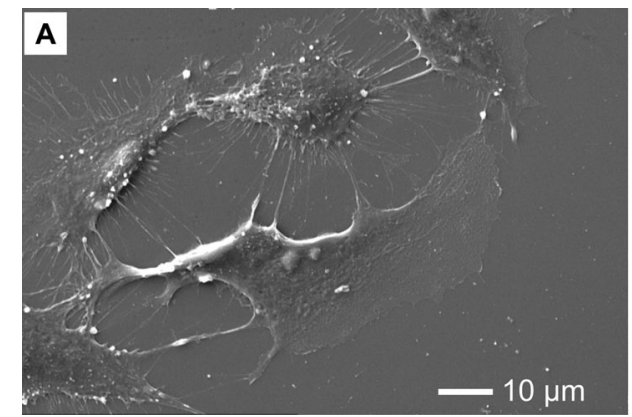

DNA $]_{5}-\mathrm{VEGF} 25$ and $[\mathrm{PDL} / \mathrm{DNA}]_{5}-\mathrm{VEGF} 250$ at individual time points $(p>0.05)$.

Morphology of endothelial cells. The morphological appearance of the endothelial cells (HUVECs) on the experimental substrates was evaluated using scanning electron microscopy. In Figure 3, representative images of endothelial cells cultured for 4 days on control and [PDL/DNA $]_{5^{-}}$ VEGF250 substrates are depicted. Endothelial cells showed a similar morphology on all types of experimental substrates. The cells exhibited a flat appearance and had several cellular extensions. After 4 and 10 days of cell culture, a visibly greater number of cells was observed on $[\mathrm{PDL} / \mathrm{DNA}]_{5}-$ VEGF25 and [PDL/DNA $]_{5}$-VEGF250 than on controls and $[\mathrm{PDL} / \mathrm{DNA}]_{5}$.

Migration of endothelial cells. An in vitro migration assay was used to study the effect of VEGF release from VEGFfunctionalized DNA-based coatings on endothelial cell migration. The migration of endothelial cells toward a concentration gradient of VEGF standards ( rVEGF $_{164}$ in AM; range $0-250 \mathrm{ng} / \mathrm{mL}$ ) is depicted in Figure 4 (inset) and was used to obtain information on the VEGF release from VEGFfunctionalized DNA-based coatings. The results show that VEGF significantly increased endothelial cell migration at concentrations ranging from 1.25 to $100 \mathrm{ng} / \mathrm{mL}(p<0.05)$. In contrast, a VEGF concentration of $250 \mathrm{ng} / \mathrm{mL}$ had no effect on endothelial cell migration.

Collected medium from the incubation of $[\mathrm{PDL} / \mathrm{DNA}]_{5^{-}}$ VEGF25 and [PDL/DNA $]_{5}$-VEGF250 experimental substrates showed that these media also increased endothelial cell migration (Fig. 4). The increased effect on endothelial cell migration was observed in medium that had been collected from 1 to at least 14 days after initiation of incubation. No statistically significant differences were observed between media collected from [PDL/DNA $]_{5}-\mathrm{VEGF} 25$ and $[\mathrm{PDL} / \mathrm{DNA}]_{5}$-VEGF250 experimental substrates $(p>0.05)$.

\section{In vivo experiment}

General observations. All 16 rats in the animal experiment remained in good health during the implantation periods

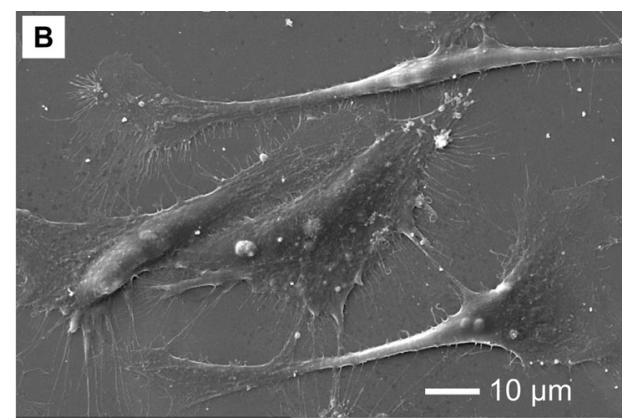

FIG. 3. Morphology of human umbilical vein endothelial cells (HUVECs) after culture on experimental substrates after 4 days. Representative scanning electron microscopy images of HUVECs on (A) control and (B) poly-D-lysine/deoxyribonucleic acid ([PDL/DNA]) $5^{-}$ vascular endothelial growth factor (VEGF)250 substrates, showing a flat morphology of endothelial cells with several cellular extensions. 


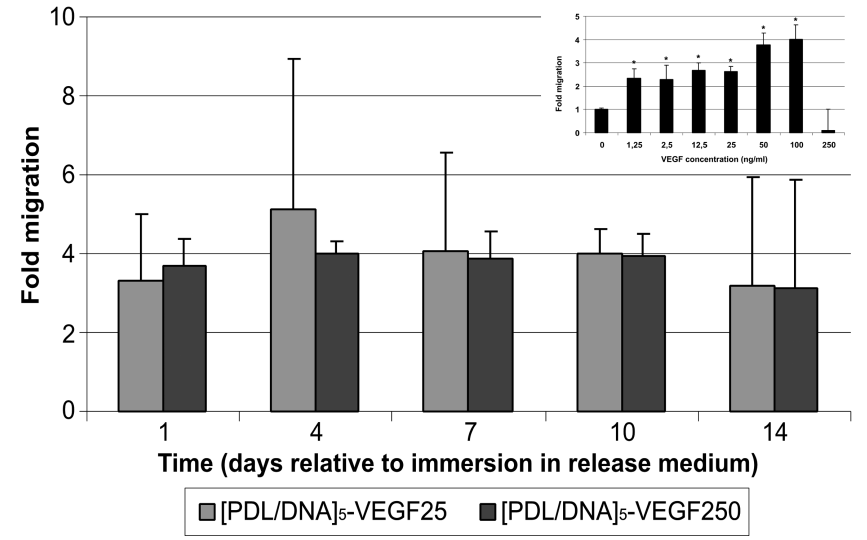

FIG. 4. Migration of human umbilical vein endothelial cells (HUVECs) in response to recombinant rat VEGF (rVEGF) 164 release from vascular endothelial growth factor (VEGF)-functionalized experimental substrates (poly-D-lysine/deoxyribonucleic acid/deoxyribonucleic acid ([PDL/DNA]) $)_{5}$-VEGF25 and $[\mathrm{PDL} / \mathrm{DNA}]_{5}$-VEGF250). Inset shows migration effects of different concentrations of VEGF $\left(\mathrm{rrVGF}_{164}\right.$; range $0-250 \mathrm{ng} / \mathrm{mL} ;{ }^{*} p<$ 0.05 compared with $0 \mathrm{ng} / \mathrm{mL}$ ).

and did not show any wound complications after surgery. At 1 week after implantation, a total of 32 implants were retrieved. At retrieval, a thin fibrous capsule surrounded all subcutaneous implants. None of the implant sites showed macroscopic signs of inflammation or adverse tissue reaction. Similarly, at 3 weeks after implantation, another 32 implants were retrieved, all of which were surrounded by a thin fibrous capsule and devoid of any macroscopic signs of inflammation or adverse tissue reactions.

Descriptive histological evaluation. Scanning electron microscopic examination of the excised implants showed that implants were sparsely covered with proteinaceous-like deposits, which were not identifiable as cellular material (data not shown). Gross evaluation of the hematoxylin/eosinstained sections of the implant-surrounding tissue capsules after 1 week of subcutaneous implantation revealed a relatively uniform tissue response to all implants (Fig. 5). Tissue at the dorsal side of the implants consisted of a fibrous capsule, connective tissue, muscle tissue, and the dermis. Occasionally, fat tissue was observed in the vicinity of the implants. The fibrous capsule was immature, reflected by the absence of flat fibrocytes at the implant side of the capsule. Few or no inflammatory cells could be observed at the implant-capsule interface or in the direct vicinity of the implants.

After 3 weeks of subcutaneous implantation, a tissue response similar to that after 1 week was observed for all implants. However, the fibrous tissue capsules had matured, as indicated by the presence of fibrocytes with a flat appearance within the tissue capsules (Fig. 6A, B). The thickness of the fibrous capsules was within the range of 5 to 30 fibroblasts, independent of implant type. No gross differences in tissue response were observed, depending on implant type.
Histomorphometrical evaluation of vascularization at the dorsal site of the implant. For the evaluation of the vascularization of the connective tissue at the dorsal site of the implants, paraffin sections were subjected to immunohistochemical techniques using a monoclonal antibody against aSMA. Representative images of the stained sections are presented in Figure 6C and D. Positive staining was observed for vascular structures and fibrous capsules. A difference was observed in immunohistochemical staining of fibrous capsules after 1 and 3 weeks of implantation, with greater staining in the more-mature fibrous capsules at 3 weeks after implantation.

Histomorphometrically, the vascularity in the tissue at the dorsal site of the implant was calculated by determining the ROI and the number of positively stained vascular structures (blood vessels) within this ROI. The histomorphometrical results are presented in Table 1 . The average ROI of the digitally imaged area in all experimental groups ranged from 0.25 to $0.28 \mathrm{~mm}^{2}$. Vascularization (VD; \# vascular structures/ $\mathrm{mm}^{2} \mathrm{ROI}$ ) of the analyzed areas showed a tendency to increase in both groups of VEGF-functionalized DNA-based coatings. However, no statistically significant differences between the individual experimental groups at individual implantation periods were found $(p>0.05)$. On the other hand, pooled data of VEGF-functionalized experimental implants $\left([\mathrm{PDL} / \mathrm{DNA}]_{5} \text {-VEGF25 + [PDL/DNA }\right]_{5}$-VEGF250) and nonfunctionalized implants (controls $+[\mathrm{PDL} / \mathrm{DNA}]_{5}$ ) showed significantly greater vascularization in the peri-implant tissue of VEGF-functionalized implants $(p<0.05)$. Vascularization in the peri-implant tissue was in the range of 102 to 155 and 66 to 142 vascular structures per $\mathrm{mm}^{2}$ at 1 and 3 weeks after subcutaneous implantation, respectively. No statistically significant differences were found for individual experimental groups at different implantation periods, except for $[\mathrm{PDL} / \mathrm{DNA}]_{5}$, which showed less vascularization after 3 weeks than after 1 week.

\section{DISCUSSION}

This study was initiated to study the effect of functionalization of a DNA-based coating with the pro-angiogenic factor VEGF on endothelial cell behavior in vitro and vascularization of the peri-implant tissue in vivo. In vitro, the effects of DNA-based coatings with small (25 ng) and large (250 ng) amounts of VEGF on endothelial cell proliferation, morphology, and migration were evaluated and compared with those of non-coated controls and non-functionalized DNA-based coatings. In vivo, these 4 types of substrates were implanted subcutaneously in the backs of rats. After implantation periods of 1 and 3 weeks, the vascularization in the direct vicinity of the implants was determined. The results of the in vitro experiments indicate that the pro-angiogenic factor VEGF remains biologically active within the functionalized DNA-based coatings, as reflected by a greater effect of functionalized DNA-based coatings on endothelial cell 


\section{control}
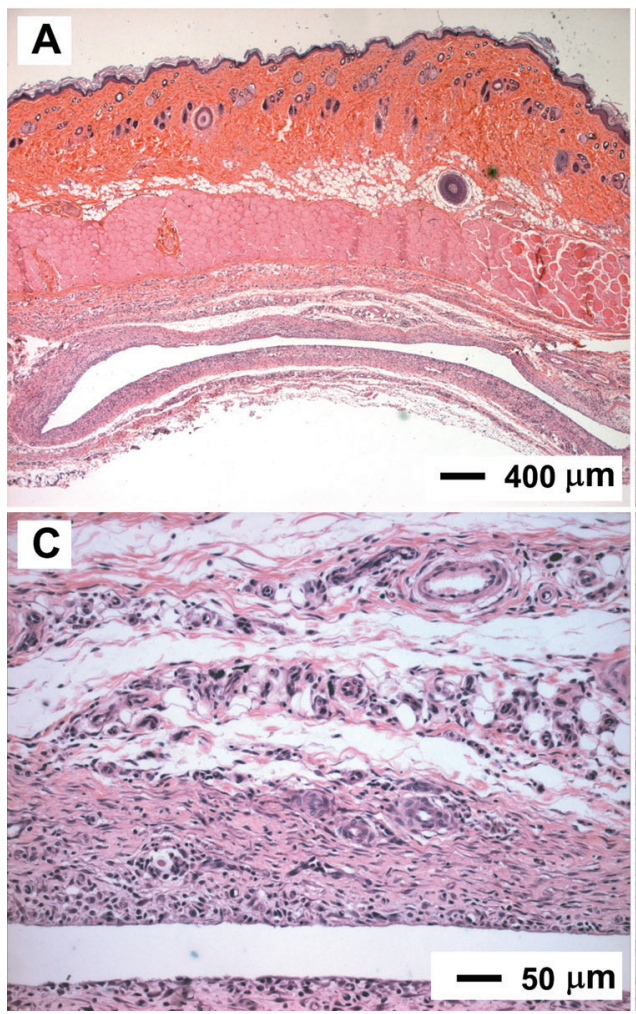

[PDL/DNA]s-VEGF25
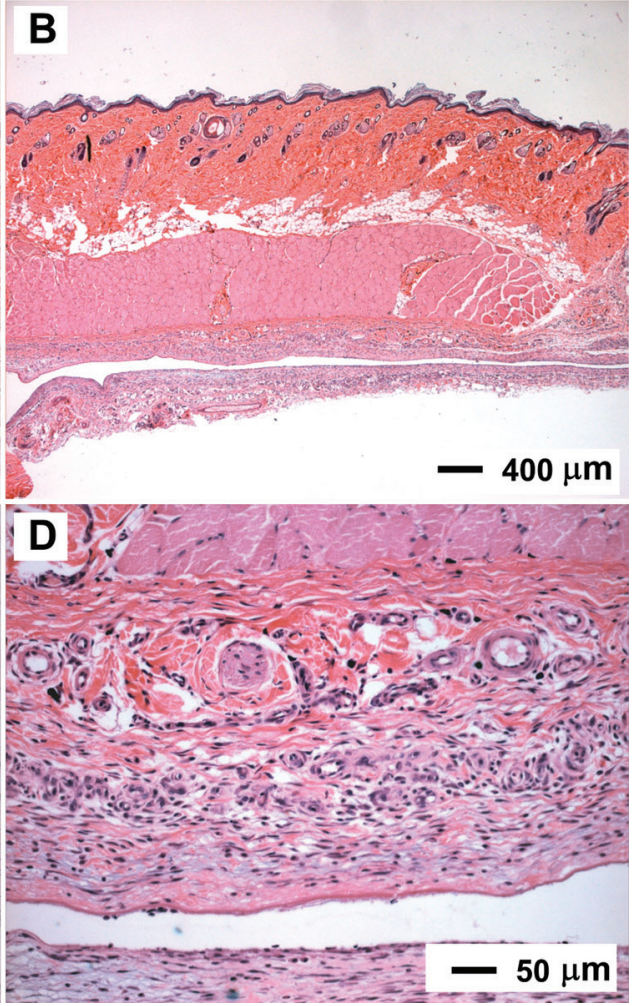

FIG. 5. Representative histological sections (hematoxylin/eosin staining) of implant-surrounding tissue 1 week after subcutaneous implantation in the back of rats. (A, B) Overview showing the fibrous tissue capsule with connective tissue, a muscle layer, and dermis at the dorsal side of the implant. (C, D) Magnification of A and B showing the thin fibrous capsule and connective tissue at the dorsal side of the implant. Color images available online at www.liebertpub.com/ten.

proliferation and migration than of non-coated controls and non-functionalized DNA-base coatings. Furthermore, greater vascularization of the peri-implant tissue surrounding VEGFfunctionalized DNA-based coatings was observed in vivo.

In an attempt to optimize the functionality of biosensors, this study was a first exploration of the use of DNA-based coatings for this purpose in view of the feasibility of their being functionalized with desired factors. ${ }^{11}$ Consequently, this study focused on functionalization of DNA-based coatings with the pro-angiogenic factor VEGF, and experiments were aimed at elucidating in vitro effects on endothelial cells and in vivo effects on implant site vascularization. The type of DNA-based coating was limited to [PDL/DNA $]_{5}$, although the fabrication and characterization of different types of DNAbased coatings have been described previously. ${ }^{8}$ The choice for a single type of DNA-based coatings is justified, because previous experiments have demonstrated that cellular and histological responses to different types of DNA-based coatings were similar. ${ }^{8-10,16}$ The amount of VEGF needed for biological activity in vitro and in vivo appears to be unclear. Amounts as small as $10 \mathrm{ng}$ have shown biological effects in vitro, ${ }^{17}$ whereas others used micrograms to induce biological effects of VEGF. ${ }^{18,19}$ It is likely that the amount needed for biological effects on vascular development are dependent on factors such as type of VEGF, release profile, and animal model. For our experiments, as a first approach, 2 amounts (25 and $250 \mathrm{ng}$ ) were chosen with a 10-fold difference.

The greater proliferation of endothelial cells on VEGFfunctionalized DNA-based coatings in the in vitro experiments demonstrates that the pro-angiogenic factor VEGF remains biologically active. Similar results were recently found for the osteo-inductive factor BMP-2, which was superficially loaded onto DNA-based coatings and accelerated the differentiation of osteoblast-like cells. ${ }^{11}$ Furthermore, our proliferation experiments demonstrated that the presence of VEGF is a prerequisite for endothelial cells (HUVECs) to proliferate, because cells cultured on controls and DNA-based coatings did not proliferate. Additionally, no negative effects of DNAbased coatings on endothelial cells were observed, which corroborates observations of others using polyelectrolyte multilayers as a substrate for endothelial cells. ${ }^{20,21}$

The efficacy of biomaterial devices in combination with growth factors depends partly on the availability of the growth factors for sensible cells. For instance, a minimal release of BMP-2 from a porous calcium phosphate scaffold appeared to be sufficient for enhanced bone formation. ${ }^{22}$ However, for our purpose, an increasing effect of VEGF on 
$[\mathrm{PDL} / \mathrm{DNA}]_{5}$

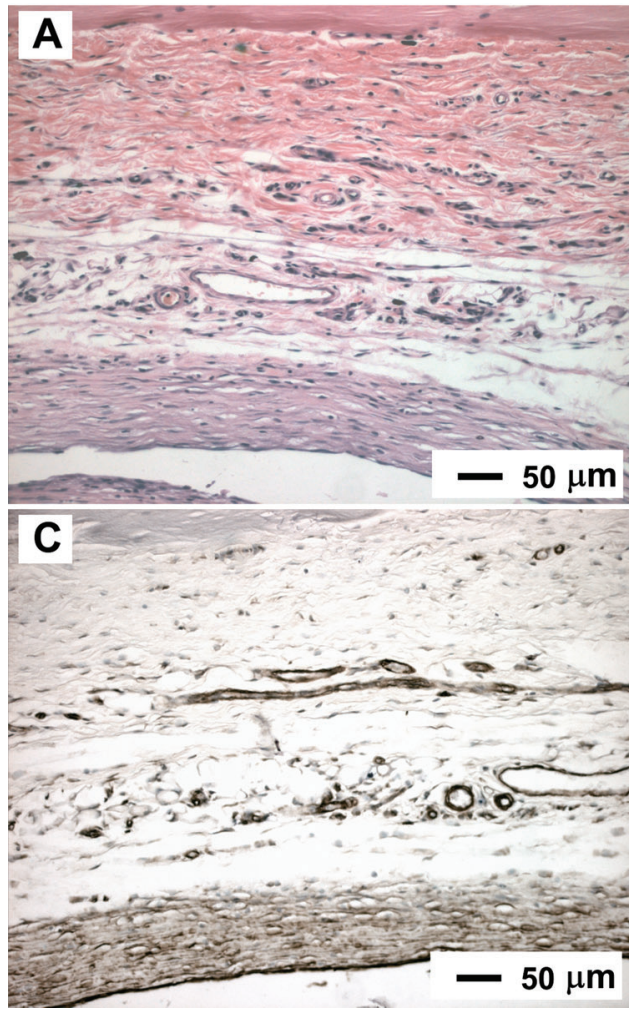

[PDL/DNA] $]_{5}$-VEGF250
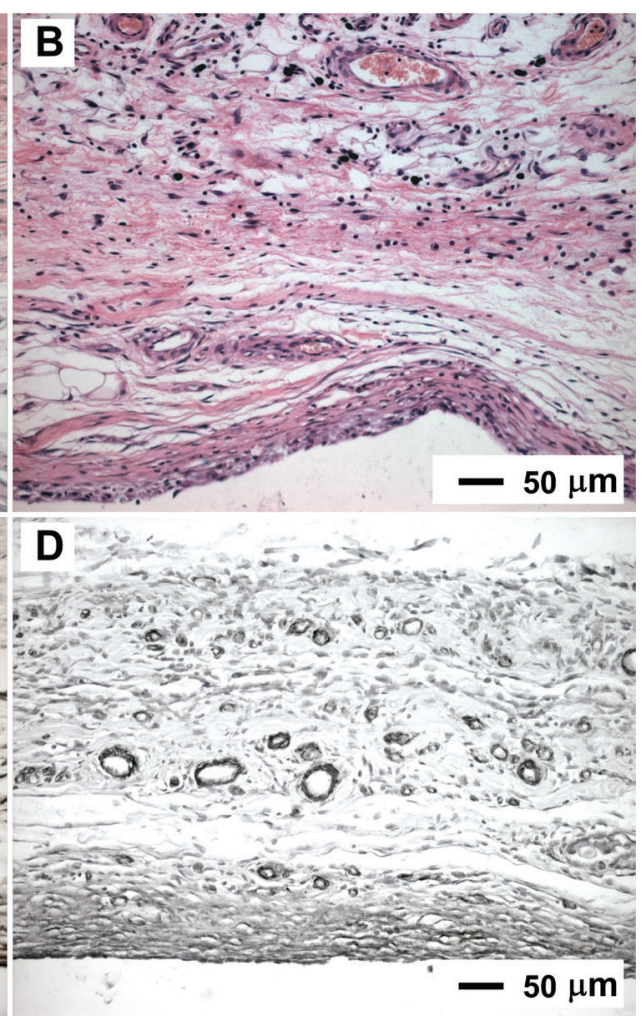

FIG. 6. Representative histological sections of implant-surrounding tissue 3 weeks after subcutaneous implantation in the back of rats. (A, B) Hematoxylin/eosin staining showing the fibrous tissue capsule with connective tissue at the dorsal side of the implant. (C, D) Immunohistochemical staining (anti-alpha smooth muscle actin) showing the blood vessels in the connective tissue at the dorsal side of the implant. Color images available online at www.liebertpub.com/ten.

vascularity in the peri-implant area in our in vivo experiment was likely to be dependent on release of the factor from the DNA-based coating. Additionally, the increased effect on the proliferation of endothelial cells observed on VEGFfunctionalized DNA-based coatings does not necessitate factor release, because bound factor might also be available for adherent cells. In light of this, the results of the migration assay indicate a continuous release of VEGF from VEGF- functionalized DNA-based coatings. Although this assay does not provide detailed information on exact amounts of VEGF released at each incubation period, it shows that released amounts are sufficient for the chemotaxis of endothelial cells. On the basis of the release profiles of BMP-2 from [PDL/ DNA $]_{5}$ coatings and the comparable iso-electric point and molecular weight of BMP-2 and VEGF, ${ }^{13}$ it can be speculated that VEGF release profiles also show an initial burst

Table 1. Histomorphometrical Analysis of Vascularization at the Dorsal Site of Subcutaneously InSerted Implants $(\mathbf{N}=\mathbf{8})$

\begin{tabular}{|c|c|c|}
\hline & $\begin{array}{l}\text { Implantation } \\
\text { time (weeks) }\end{array}$ & $\begin{array}{l}\text { Vascularization (mean \# vascular } \\
\text { structures } / \mathrm{mm}^{2} \pm \text { standard deviation) }\end{array}$ \\
\hline Control & & $111 \pm 55$ \\
\hline$[\mathrm{PDL} / \mathrm{DNA}]_{5}$ & & 7939 \\
\hline [PDL/DNA] $]_{5}$-VEGF25 & 1 & $155 \pm 46$ \\
\hline$[\mathrm{PDL} / \mathrm{DNA}]_{5}-\mathrm{VEGF} 250$ & & $102 \pm 40$ \\
\hline Control & & $102 \pm 30$ \\
\hline$[\mathrm{PDL} / \mathrm{DNA}]_{5}$ & & ل $66 \pm 40$ \\
\hline$[\mathrm{PDL} / \mathrm{DNA}]_{5}-\mathrm{VEGF} 25$ & 3 & $142 \pm 54$ \\
\hline$[\mathrm{PDL} / \mathrm{DNA}]_{5}-\mathrm{VEGF} 250$ & & $136 \pm 65$ \\
\hline
\end{tabular}

$p<0.05$.

PDL, poly-D-lysine; DNA, deoxyribonucleic acid; VEGF, vascular endothelial growth factor. 
release followed by a sustained release for several weeks. This would indicate that the initial VEGF burst release would approximate 17 and $170 \mathrm{ng}$ for DNA-based coatings functionalized with 25 and $250 \mathrm{ng}$ VEGF, respectively. The subsequent sustained VEGF release would then approximate 0.5 and $5 \mathrm{ng}$ per week, respectively. Although the exact released amounts are not clear, the amounts released in the collected release media are apparently sufficient for an effect on endothelial cell migration.

Several animal models for studying angiogenesis have been described in detail, including dorsal skinfold chambers ${ }^{23}$ and ear pinnae $;{ }^{24}$ however, these models have limitations regarding implant size, ${ }^{25}$ which impedes their use for our implants. Additionally, because the focus of our study was to monitor vascularity effects of the peri-implant tissue of subcutaneous implants, we used a simple subcutaneous implantation model in rats. Inevitably, this simple approach for the detection of effects on vascularization has several drawbacks. For instance, the confinement of the area for evaluation of the effects of VEGF on vascularization was difficult to standardize. In contrast to previous studies, in which vascularization was determined in porous implants, ${ }^{26,27}$ the use of solid implants is associated with concessions in peri-implant area. The excision of the implants, allowing deformations of the fibrous capsule and surrounding tissue during subsequent histological processing further hampered standardization of the peri-implant area. Nevertheless, the approach used in this study allows the comparison of vessel density in the peri-implant area, in which the maximum distance of vessels to the implant surface approximates $600 \mu \mathrm{m}$ (image height of $\alpha$ SMA-stained sections $\approx 650 \mu \mathrm{m}$ ). The results show no significant effects of individual VEGFfunctionalized DNA-based coatings on peri-implant vessel density. However, significantly greater peri-implant vascularity was observed in VEGF-functionalized DNA-based coatings than in controls and non-functionalized DNA-based coatings. Furthermore, a significant decrease in vascularity from 1 to 3 weeks after implantation was observed in tissue surrounding non-functionalized DNA-based coatings. This observation might be related to the effect of DNA-based coatings on fibroblasts, ${ }^{9,10}$ which form the fibrous capsule, and subsequent intercellular signaling between fibroblasts and cells in their surroundings. However, the actual cause for this observation remains unclear and should be addressed in future experiments.

Although the functionalization of DNA-based coatings in this study was restricted to a single angiogenic factor, considerable debate is ongoing on the necessity for combined growth factor delivery for angiogenesis and vessel maturation. Indeed, synergistic effects of combined administration of VEGF and basic fibroblast growth factor have been demonstrated on collateral circulation in a hind limb ischemia model. ${ }^{28}$ Additionally, Peattie et al. demonstrated enhancement of angiogenic responses in a murine ear pinnae model using dual delivery of VEGF and keratinocyte growth factor. ${ }^{29}$ Such combined delivery vehicles could also be fabri- cated using DNA-based coatings, because the mechanism of fabrication has been demonstrated to be applicable for compartmentalization of such polyelectrolyte multilayers, ${ }^{30}$ which would allow temporal control over growth factor release.

\section{CONCLUSION}

This study demonstrates that the functionalization of DNAbased coatings with the pro-angiogenic factor VEGF results in greater proliferation and migration of endothelial cells in vitro, indicating that the VEGF retained its biological activity. In an in vivo implantation experiment in rats, greater vascularization of the peri-implant tissue surrounding VEGFfunctionalized DNA-based coatings was observed.

\section{ACKNOWLEDGMENTS}

The authors would like to acknowledge Nichiro Corporation (Kawasaki-city, Japan) for providing DNA. Scanning electron microscopy was performed in collaboration with the Microscopical Imaging Center of the Nijmegen Center for Molecular Life Sciences. Ms. Natasja van Dijk, dr. Weibo Zhang (Department of Periodontology and Biomaterials), and Mr. René van Rheden (Department of Orthodontics and Oral Biology) are acknowledged for their help with histological preparations and immunohistochemical staining. Mr. Vincent Cuijpers (Department of Periodontology and Biomaterials) is acknowledged for assistance with histomorphometrical analyses. This research was financially supported by the Technology Foundation STW, applied science division of Netherlands Organization for Scientific Research (Nederlandse Organisatie voor Wetenschappelijk onderzoek, NWO) and the technology program of the Ministry of Economic Affairs (Grant NKG.5758).

\section{REFERENCES}

1. Sharkawy, A.A., B. Klitzman, G.A. Truskey, and W.M. Reichert. 1997. Engineering the tissue which encapsulates subcutaneous implants. I. Diffusion properties. J Biomed Mater Res 37:401-12.

2. Woodward, S.C. 1982. How fibroblasts and giant cells encapsulate implants: considerations in design of glucose sensors. Diabetes Care 5:278-81.

3. Gerritsen, M., J.A. Jansen, A. Kros, D.M. Vriezema, N.A.J.M. Sommerdijk, R.J.M. Nolte, J.A. Lutterman, S.W. Van Hovell, and A. Van der Gaag. 2001. Influence of inflammatory cells and serum on the performance of implantable glucose sensors. J Biomed Mater Res 54:69-75.

4. Pepper, M.S. 1997. Manipulating angiogenesis. From basic science to the bedside. Arterioscler Thromb Vasc Biol 17: 605-19.

5. Klagsbrun, M. and M.A. Moses. 1999. Molecular angiogenesis. Chem Biol 6:R217-24. 
6. Nomi, M., A. Atala, P.D. Coppi, and S. Soker. 2002. Principals of neovascularization for tissue engineering. Mol Aspects Med 23:463-83.

7. Li, J., Y.P. Zhang, and R.S. Kirsner. 2003. Angiogenesis in wound repair: angiogenic growth factors and the extracellular matrix. Microsc Res Tech 60:107-14.

8. van den Beucken, J.J.J.P., M.R.J. Vos, P.C. Thune, T. Hayakawa, T. Fukushima, Y. Okahata, X.F. Walboomers, N.A.J.M. Sommerdijk, R.J.M. Nolte, and J.A. Jansen. 2006. Fabrication, characterization, and biological assessment of multilayered DNA-coatings for biomaterial purposes. Biomaterials 27:691-701.

9. van den Beucken, J.J.J.P., X.F. Walboomers, M.R.J. Vos, N.A.J.M. Sommerdijk, R.J.M. Nolte, and J.A. Jansen. 2006. Cyto- and histocompatibility of multilayered DNA-coatings on titanium. J Biomed Mater Res A 77A:202-211.

10. van den Beucken, J.J.J.P., X.F. Walboomers, M.R.J. Vos, N.A.J.M. Sommerdijk, R.J.M. Nolte, and J.A. Jansen. 2006. Biological responses to multilayered DNA-coatings. J Biomed Mater Res B Sep 12; [Epub ahead of print].

11. van den Beucken, J.J.J.P., X.F. Walboomers, O.C. Boerman, M.R.J. Vos, N.A.J.M. Sommerdijk, T. Hayakawa, T. Fukushima, Y. Okahata, R.J.M. Nolte, and J.A. Jansen. 2006. Functionalization of multilayered DNA-coatings with bone morphogenetic protein 2. J Control Release 113:63-72.

12. Decher G. 1997. Fuzzy nanoassemblies: toward layered polymeric multicomposites. Science 277:1232-1237.

13. Yamamoto, M., Y. Ikada, and Y. Tabata. 2001. Controlled release of growth factors based on biodegradation of gelatin hydrogel. J Biomater Sci Polym Ed 12:77-88.

14. Kobayashi, H., N. Tsuruchi, K. Sugihara, T. Kaku, T. Saito, T. Kamura, N. Tsukamoto, H. Nakano, and S. Taniguchi. 1993. Expression of alpha-smooth muscle actin in benign or malignant ovarian tumors. Gynecol Oncol 48:308-13.

15. Parker, J.A., X.F. Walboomers, J.W. Von Den Hoff, J.C. Maltha, and J.A. Jansen. 2003. Soft tissue reaction to microgrooved poly-L-lactic acid implants loaded with transforming growth factor beta(3). Tissue Eng 9:117-26.

16. van den Beucken, J.J.J.P., X.F. Walboomers, M.R.J. Vos, N.J.A.M. Sommerdijk, R.J.M. Nolte, and J.A. Jansen. 2006. Macrophage behavior on multilayered DNA-coatings in vitro. J Biomed Mater Res A Oct 9; [Epub ahead of print].

17. Rebai, O., J. Le Petit-Thevenin, N. Bruneau, D. Lombardo, and A. Verine. 2005. In vitro angiogenic effects of pancreatic bile salt-dependent lipase. Arterioscler Thromb Vasc Biol 25: 359-64.

18. Steffens, G.C., C. Yao, P. Prevel, M. Markowicz, P. Schenck, E.M. Noah, and N. Pallua. 2004. Modulation of angiogenic potential of collagen matrices by covalent incorporation of heparin and loading with vascular endothelial growth factor. Tissue Eng 10:1502-9.

19. Ravin, A.G., K.C. Olbrich, L.S. Levin, A.L. Usala, and B. Klitzman. 2001. Long- and short-term effects of biological hydrogels on capsule microvascular density around implants in rats. J Biomed Mater Res 58:313-8.

20. Boura, C., P. Menu, E. Payan, C. Picart, J.C. Voegel, S. Muller, and J.F. Stoltz. 2003. Endothelial cells grown on thin polyelectrolyte mutlilayered films: an evaluation of a new versatile surface modification. Biomaterials 24:3521-30.
21. Boura, C., H. Kerdjoudj, V. Moby, D. Vautier, D. Dumas, P. Schaaf, J.C. Voegel, J.F. Stoltz, and P. Menu. 2006. Initial adhesion of endothelial cells on polyelectrolyte multilayer films. Biomed Mater Eng 16:S115-21.

22. Ruhe, P.Q., H.C. Kroese-Deutman, J.G.C. Wolke, P.H. Spauwen, and J.A. Jansen. 2004. Bone inductive properties of rhBMP-2 loaded porous calcium phosphate cement implants in cranial defects in rabbits. Biomaterials 25:2123-32.

23. Rucker, M., M.W. Laschke, D. Junker, C. Carvalho, A. Schramm, R. Mulhaupt, N.C. Gellrich, and M.D. Menger. 2006. Angiogenic and inflammatory response to biodegradable scaffolds in dorsal skinfold chambers of mice. Biomaterials 27:5027-38.

24. Pike, D.B., S. Cai, K.R. Pomraning, M.A. Firpo, R.J. Fisher, X.Z. Shu, G.D. Prestwich, and R.A. Peattie. 2006. Heparinregulated release of growth factors in vitro and angiogenic response in vivo to implanted hyaluronan hydrogels containing VEGF and bFGF. Biomaterials 27:5242-51.

25. Laschke, M.W., Y. Harder, M. Amon, I. Martin, J. Farhadi, A. Ring, N. Torio-Padron, R. Schramm, M. Rucker, D. Junker, J.M. Ha, C. Carvalho, M. Heberer, G. Germann, B. Vollmar, and M.D. Menger. 2006. Angiogenesis in tissue engineering: breathing life into constructed tissue substitutes. Tissue Eng 12:2093-104.

26. Ribatti, D., B. Nico, L. Morbidelli, S. Donnini, M. Ziche, A. Vacca, L. Roncali, and M. Presta. 2001. Cell-mediated delivery of fibroblast growth factor-2 and vascular endothelial growth factor onto the chick chorioallantoic membrane: endothelial fenestration and angiogenesis. J Vasc Res 38:389-97.

27. Kidd, K.R. and S.K. Williams. 2004. Laminin-5-enriched extracellular matrix accelerates angiogenesis and neovascularization in association with ePTFE. J Biomed Mater Res A 69:294-304.

28. Asahara, T., C. Bauters, L.P. Zheng, S. Takeshita, S. Bunting, N. Ferrara, J.F. Symes, and J.M. Isner. 1995. Synergistic effect of vascular endothelial growth factor and basic fibroblast growth factor on angiogenesis in vivo. Circulation 92: II365-71.

29. Peattie, R.A., E.R. Rieke, E.M. Hewett, R.J. Fisher, X.Z. Shu, and G.D. Prestwich. 2006. Dual growth factor-induced angiogenesis in vivo using hyaluronan hydrogel implants. Biomaterials 27:1868-75.

30. Garza, J.M., P. Schaaf, S. Muller, V. Ball, J.F. Stoltz, J.C. Voegel, and P. Lavalle. 2004. Multicompartment films made of alternate polyelectrolyte multilayers of exponential and linear growth. Langmuir 20:7298-302.

Address reprint requests to: John A. Jansen, D.D.S., Ph.D. Radboud University Nijmegen Medical Center Department of Periodontology \& Biomaterials PO Box 9101 6500 HB Nijmegen The Netherlands

E-mail: j.jansen@dent.umcn.nl 